\title{
Analysis of Octamer-Binding Transcription Factors Oct2 and Oct1 and their coactivator BOB.1/OBF.1 in Lymphomas
}

Ana-Isabel Sáez, M.D., Ph.D., María-Jesús Artiga, Ph.D., Margarita Sánchez-Beato, Ph.D., Lydia Sánchez-Verde, Juan-Fernando García, M.D., Francisca-Inmaculada Camacho, M.D., Renato Franco, M.D., Miguel A. Piris, M.D., Ph.D.

Molecular Pathology Program, Centro Nacional de Investigaciones Oncológicas Carlos III, Madrid, Spain

Oct1 and Oct2 are transcription factors of the POU homeo-domain family that bind to the Ig gene octamer sites, regulating B-cell-specific genes. The function of these transcription factors is dependent on the activity of B-cell-restricted coactivators such as BOB.1/OBF.1. Independent studies of the expression of these proteins in non-Hodgkin's lymphoma have been restricted to single markers, and most lack data concerning immunohistochemical expression. Thus, we have investigated the expression of Oct1, Oct2, and BOB.1/OBF.1 in human reactive lymphoid tissue and in a series of 140 Hodgkin and non-Hodgkin's lymphomas.None of these proteins was found to be restricted to B cells, although only $B$ cells expressed high levels of all three markers. Additionally, germinal center B cells showed stronger Oct2 and BOB.1/OBF.1 staining. Consequently, most B-cell lymphomas showed reactivity for all three antibodies. Oct 2 expression was significantly higher in germinal center-derived lymphomas, although other B-cell lymphomas also displayed a high level of Oct2 expression.Although T-cell lymphomas and Hodgkin's lymphomas expressed some of these proteins, they commonly exhibited less reactivity than B-cell lymphomas.Despite not being entirely cell-specific, the strong nuclear expression of Oct2 and BOB.1/OBF.1 by germinal centerderived lymphomas makes these antibodies a potentially useful tool in lymphoma diagnosis.

Copyright $(2002$ by The United States and Canadian Academy of Pathology, Inc.

VOL. 15, NO. 3, P. 211, 2002 Printed in the U.S.A.

Date of acceptance: November 19, 2001.

This study was supported by grants from the Fondo de Investigaciones Sanitarias (FIS 00/9310), Ministerio de Sanidad y Consumo, and from the Comisión Interministerial de Ciencia y Tecnología (1FD97-0431), Spain. Address reprint requests to: Miguel A. Piris, M.D., Centro Nacional de Investigaciones Oncologicas, Programa de Patologia Molecular, Melchor Fernandez Almagro, No 3, 28029 Madrid, Spain; e-mail: mapiris@cnio.es; fax: 34-91-224-69-23.
KEY WORDS: BOB1, Lymphoma, Oct1, Oct2, Transcription factors.

Mod Pathol 2002;15(3):211-220

The expression of light and heavy IgH genes and other important genes for B-cell differentiation and proliferation is controlled by octamer motifs (1-3). These motifs are the binding regions for a family of transcription factors known as the POU family (4). The members of this family reach their maximum transactivating activity through binding to various coactivators (5). One of these coactivators, BOB.1/ OBF.1, has been cloned $(6,7)$.

The most relevant members of the POU transcription factor family involved in the control of expression of the IgH genes are Oct2, which is predominantly expressed in B cells, and the more ubiquitous Oct1 $(8,9)$. Oct2 and Oct1 seem to be essential for the promoter and enhancer function of IgH genes $(10,11)$.

Oct2 participates in the control of important B-specific genes, such as the Ig gene and others involved in proliferation and differentiation, including CD20, CRISP-3, and CD36 (12-15). Moreover, despite the scarce evidence for Oct2 expression in $\mathrm{T}$ cells, it has been shown that this factor participates in transcriptional regulation during T-cell activation (16).

Functionally, Oct2 activity is dependent on phosphorylation and alternative splicing (17-21), although it seems that the level of its expression can be used as a marker of B-cell lineage and differentiation $(10,11,22,23)$. The activity of Octl can also be modified by phosphorylation (21). Another important factor regulating the Oct function is the capacity of some octamer motifs to induce dimerization of Oct 2 and Oct1, conferring additional activity on these factors and regulating BOB.1/OBF.1 recruitment. In fact, it has been proposed that $\operatorname{IgV}_{\mathrm{H}}$ promoter depends almost exclusively on dimerization of Oct1, whereas V $\kappa$ promoters and 3'-IgH en- 
hancer depend on Oct and BOB.1/OBF.1 recruitment. However, elevated expression of secondary isotypes depends on both Octs and BOB.1/OBF.1 (24). Several studies of Oct2 expression have shown a low level of expression in pre-B, T-cell, myelomonocytic, and epithelial cell lines, whereas all mature B-cell lines display high levels of expression (25-28). A previous analysis of Oct2 expression in primary Hodgkin's lymphoma (HL) and cell lines derived from it showed that all the tumor cells analyzed had high levels of expression and activity, suggesting a common B-cell origin for all types of HLs (27). Nevertheless, these findings were not confirmed in some subsequent analysis of the same cell lines $(29,30)$. Additionally, these recent report showed Oct2 expression to be a useful marker for lymphocyte-predominant HL (LPHL), which is absent in the vast majority of cases of the classical form of HL.

Knockout mice for Oct2 die shortly after birth, for unexplained reasons. This observation supports the suggestion that Oct2 plays a significant role during embryonic development. These mice also display numerous alterations in the maturation of B lymphocytes in response to antigens and a dramatic reduction in the number of plasma cells, implying that the late steps of the immune response are dependent on this protein (23).

Studies on the expression of Octl have demonstrated a high level of expression in pre-B cell lines $(25,26)$ when the levels of expression of Oct2 and BOB.1/OBF.1 are both low, suggesting that Oct1 could play a major role in the control of Ig transcription during this phase of B-cell development (10). No immunohistochemical studies on Octl expression in NHL have yet been published, although its ubiquitous expression has been described in a variety of cell lines.

BOB.1/OBF.1 (or OCA-B) seems to play a critical role, interacting with both Oct1 and Oct2 and upregulating octamer transactivating activities (31-33). BOB.1/OBF.1 specificity is determined by its expression, which is restricted to lymphoid tissue $(5,33)$, by its specific binding to Oct2 and Oct $1(7,34)$, and by its capacity for binding to specific regions of DNA, such as the Ig $\kappa$ promoter (35-37). Moreover, posttranscriptional regulation of BOB.1/OBF.1 activity has been demonstrated by phosphorylation. In B cells, it is constitutively phosphorylated, whereas in $\mathrm{T}$ cells, phosphorylation is necessary for BOB.1/OBF.1 activity (38).

Although it has been shown in different cell lines that BOB.1/OBF.1 is expressed at all stages of B-cell development $(7,33,34,39)$, in vivo immunohistochemical studies have demonstrated selective expression in germinal center and germinal centerderived lymphomas (40). Accordingly, activation of the BOB.1/OBF.1 promoter is observed in response to signals inducing the formation of germinal centers, such as CD40 or IL-4 $(41,42)$. BOB.1/OBF.1deficient mice maintain the expression of IgH and $\mathrm{L}$ genes with normal IgM levels but lack germinal centers and have a reduced number of B cells, and consequently a strong reduction of switched Ig isotypes (43).

Because the expression of these transcription factors and coactivators could help define the stages of B-cell development and consequently make it possible to define tumoral entities more precisely, we immunostained benign lymphoid tissues and a large group of lymphomas to look for specific patterns of expression and to analyze the correlation of the expression of these factors between tumoral and normal subpopulations. The recent description by Stein and coworkers of the expression pattern of these transcription factors in HL, initially presented at the Meeting of the European Society for Hematopathology, London, 2000, provided further stimulus for carrying out this study (29).

\section{MATERIALS AND METHODS}

\section{Tissue Samples}

Formalin-fixed and paraffin-embedded normal tissues and tumor specimens were obtained from the routine files of the Molecular Pathology Department of the Centro Nacional de Investigaciones Oncológicas Carlos III, Madrid, Spain. Diagnosis was performed according to standard procedures, including immunohistochemistry and CDRII, CDRIII, and TCR $\gamma$ rearrangement studies by polymerase chain reaction, when necessary. Lymphoid tumors were classified according to the Revised European-American classification of Lymphoid neoplasms (50).

Samples of reactive lymphoid tissue including tonsil (10 cases), lymph nodes (12 cases), spleen (6 cases) and thymus (2 cases) were analyzed. Tumor specimens from 140 non-HL (NHL) and 25 HL cases were included in the study. The distribution of the lymphoma types is shown in Table 1.

\section{Antibodies}

Immunohistochemical staining of BOB.1/OBF.1 protein was performed with the polyclonal antibody (C-20) sc-955 from Santa Cruz Laboratories (Santa Cruz, CA), diluted 1:7000, and generated against a peptide mapping to the carboxy terminus of a Bob1 of human origin. Oct2 protein was detected with rabbit polyclonal antibody Oct2 (C-20) sc-233 (Santa Cruz) and raised against a peptide mapping to the carboxy terminus of Oct2. Oct1 


\begin{tabular}{|c|c|c|c|c|c|c|c|c|c|c|c|c|c|}
\hline \multirow{2}{*}{ Lymphoid Tumor } & \multirow{2}{*}{$\mathrm{N}$} & \multicolumn{4}{|c|}{ Oct2 } & \multicolumn{4}{|c|}{ Oct1 } & \multicolumn{4}{|c|}{ BOB.1/OBF.1 } \\
\hline & & +++ & ++ & + & - & +++ & ++ & + & - & +++ & ++ & + & - \\
\hline \multicolumn{14}{|l|}{ B-cell lymphoma } \\
\hline B-cell chronic lymphocytic leukemia & 2 & 1 & 1 & 0 & 0 & 0 & 2 & 0 & 0 & 0 & 2 & 0 & 0 \\
\hline Mantle cell lymphoma & 6 & 0 & 6 & 0 & 0 & 0 & 4 & 2 & 0 & 0 & 5 & 1 & 0 \\
\hline Extranodal marginal zone B-cell lymphoma & 5 & 3 & 2 & 0 & 0 & 3 & 2 & 0 & 0 & 4 & 1 & 0 & 0 \\
\hline Nodal marginal zone B-cell lymphoma & 4 & 3 & 1 & 0 & 0 & 4 & 0 & 0 & 0 & 0 & 4 & 0 & 0 \\
\hline Splenic marginal zone B-cell lymphoma & 6 & 3 & 3 & 0 & 0 & 0 & 4 & 2 & 0 & 1 & 5 & 0 & 0 \\
\hline Follicular lymphoma & 10 & 10 & 0 & 0 & 0 & 4 & 6 & 0 & 0 & 6 & 4 & 0 & 0 \\
\hline Lymphoplasmacytic lymphoma & 4 & 3 & 1 & 0 & 0 & 2 & 1 & 1 & 0 & 2 & 1 & 1 & 0 \\
\hline Multiple myeloma & 1 & 1 & 0 & 0 & 0 & 0 & 1 & 0 & 0 & 0 & 1 & 0 & 0 \\
\hline Diffuse large B-cell lymphoma & 47 & 33 & 10 & 2 & 2 & 9 & 29 & 9 & 0 & 22 & 23 & 2 & 0 \\
\hline Burkitt's lymphoma & 10 & 10 & 0 & 0 & 0 & 10 & 0 & 0 & 0 & 10 & 0 & 0 & 0 \\
\hline Total & 94 & 67 & 24 & 2 & 2 & 32 & 49 & 14 & 0 & 45 & 46 & 4 & 0 \\
\hline \multicolumn{14}{|l|}{ T-cell lymphoma } \\
\hline Angioimmunoblastic T lymphoma & 4 & 0 & 2 & 2 & 0 & 0 & 3 & 1 & 0 & 0 & 0 & 3 & 1 \\
\hline Lymphoblastic T lymphoma & 4 & 0 & 0 & 2 & 2 & 0 & 4 & 0 & 0 & 0 & 2 & 1 & 1 \\
\hline Extranodal NK/T-cell lymphoma & 2 & 0 & 1 & 0 & 1 & 0 & 1 & 1 & 0 & 0 & 0 & 0 & 2 \\
\hline Peripheral T-cell lymphoma & 5 & 0 & 2 & 1 & 2 & 0 & 4 & 1 & 0 & 0 & 0 & 5 & 0 \\
\hline Anaplastic large T-cell lymphoma & 2 & 0 & 0 & 1 & 1 & 0 & 1 & 1 & 0 & 0 & 0 & 2 & 0 \\
\hline Total & 17 & 0 & 5 & 6 & 6 & 0 & 13 & 4 & 0 & 0 & 2 & 11 & 4 \\
\hline \multicolumn{14}{|l|}{ Hodgkin's lymphoma } \\
\hline Mixed cellularity Hodgkin's lymphoma & 12 & 4 & 5 & 1 & 2 & 1 & 6 & 5 & 0 & 0 & 5 & 3 & 4 \\
\hline Nodular sclerosis Hodgkin's lymphoma & 8 & 0 & 1 & 3 & 4 & 0 & 3 & 4 & 1 & 0 & 1 & 5 & 2 \\
\hline $\begin{array}{l}\text { Lymphocyte depletion Hodgkin's } \\
\text { lymphoma }\end{array}$ & 2 & 0 & 1 & 1 & 0 & 0 & 2 & 0 & 0 & 0 & 1 & 1 & 0 \\
\hline $\begin{array}{l}\text { Lymphocyte-rich classical Hodgkin's } \\
\text { lymphoma }\end{array}$ & 2 & 0 & 0 & 1 & 1 & 0 & 2 & 0 & 0 & 0 & 1 & 0 & 1 \\
\hline $\begin{array}{l}\text { Lymphocyte-predominant Hodgkin's } \\
\text { lymphoma }\end{array}$ & 5 & 5 & 0 & 0 & 0 & 3 & 2 & 0 & 0 & 1 & 4 & 0 & 0 \\
\hline Total & 29 & 9 & 7 & 6 & 7 & 4 & 15 & 9 & 1 & 1 & 12 & 9 & 7 \\
\hline
\end{tabular}

protein was detected with mouse monoclonal antibody 12F11 from Santa Cruz diluted 1:10 and was raised against a recombinant protein corresponding to amino acids $462-760$, which map to the carboxy terminus.

CD20 (L26, DAKO, Glostrup, Denmark), CD79a (JCB 117, DAKO), CD3 (Polyclonal, DAKO), bcl-6 (P6-B6p, DAKO) and CD43 (DFT1, DAKO) antibodies were also used in the study.

\section{Immunostaining Technique}

Immunostaining techniques were performed in paraffin-embedded tissue. A heat-induced epitope retrieval step was performed in a solution of sodium citrate buffer before incubation with antibodies. Xylene-dewaxed and alcohol-rehydrated paraffin sections were placed in Coplin jars filled with $0.01 \mathrm{M}$ trisodium citrate solution and were heated for 2 minutes in a conventional pressure cooker. After heating, slides were rinsed in cool running water for 5 minutes. They were then quickly washed in Tris buffered saline, $\mathrm{pH}$ 7.4, and incubated with primary antibodies (Abs).

After incubation with the primary antibody (Ab), immunodetection was performed with biotinylated anti-mouse Ig, followed by peroxidaselabeled streptavidin-biotin (LSAB-DAKO) with diaminobenzidine chromogen as substrate. All immunostaining was performed using the Tech-
Mate 500 (DAKO) automatic immunostaining device.

Incubation omitting the specific $\mathrm{Ab}$, as well as incubation including unrelated Abs, was used as controls with the technique. Vimentin was used as the control of antigenic preservation and successful antigenic retrieval.

For double immunostaining, CD20/Oct2, CD20/ BOB.1/OBF.1, CD43/BOB.1/OBF.1, and CD3/Oct1 were studied in paraffin sections. Briefly, the first antigen, CD20, CD43, or CD3 was detected using the EnVision Alkaline Phosphatase System (alkaline phosphatase-labeled polymer conjugated to affinity-purified goat anti-rabbit and goat antimouse immunoglobulins; DAKO) and developed with Fast-Red as chromogen. Thereafter, the sections were incubated with the second antibody, Oct2, BOB.1/OBF.1, or Oct1 and detected with EnVision Peroxidase mono link (DAKO), using 3,3'diaminobenzidine as the chromogen.

Expression of Oct2, Oct1, and BOB.1/OBF.1 was scored semiquantitatively, taking into consideration the number of positive cells and the signal intensity and with reference to that observed in normal cells. The categories were +++ (intense staining, like the staining of the three markers in normal germinal center cells), ++ (moderate intensity staining), + (weak but distinct staining), and $-/+$ for a weak positivity in only a proportion of the 

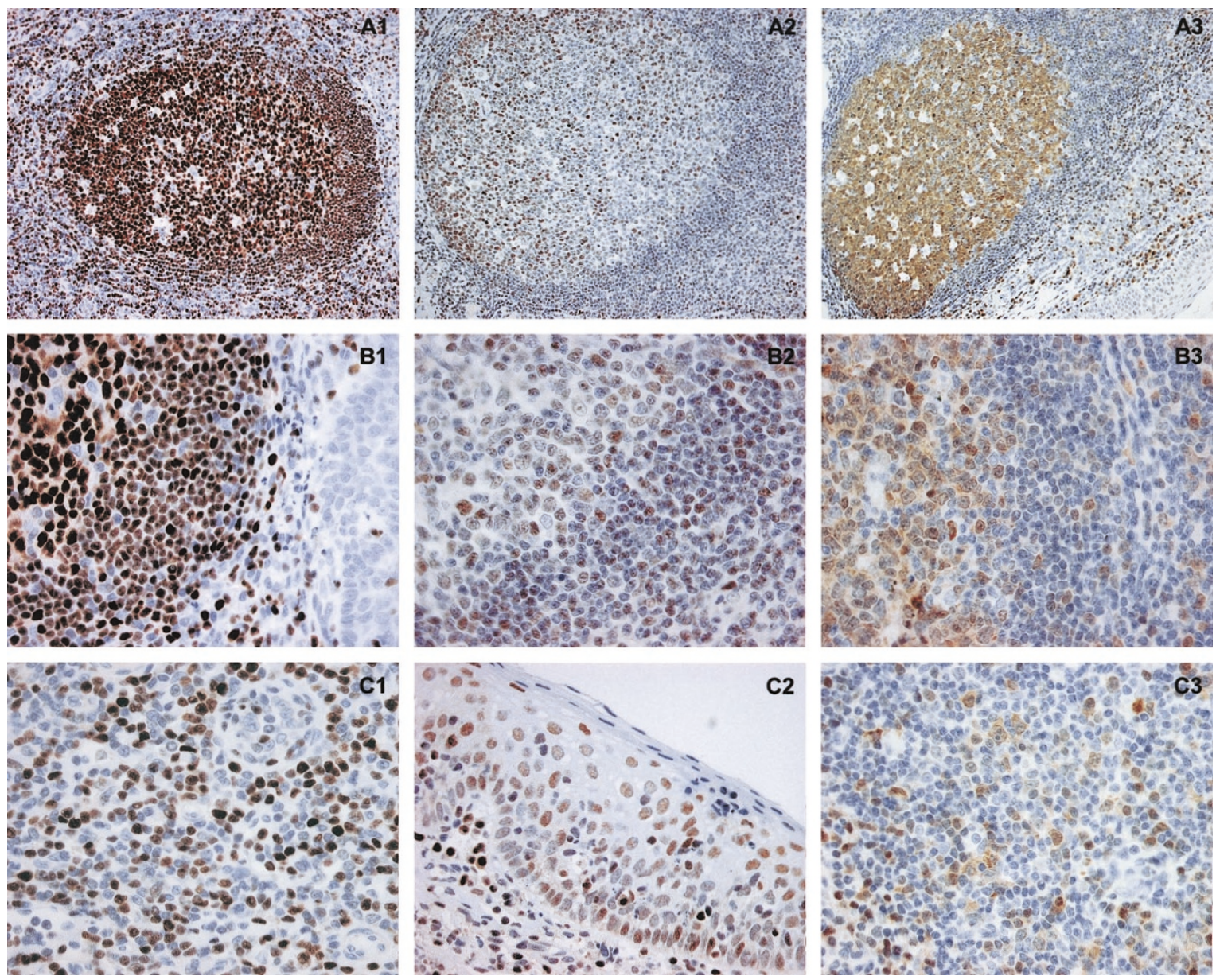

FIGURE 1. Expression of Oct2, Oct1, and BOB.1/OBF.1 in reactive lymphoid tissue from human tonsil. A, sections showing strong staining for Oct2 (A1), Oct1 (A2), and BOB.1/OBF.1 (A3) in germinal center lymphocytes. B, detail showing weaker expression in mantle zone lymphocytes than in germinal center lymphocytes for Oct2 (B1), Oct1 (B2), and BOB.1/OBF.1 (B3). The staining for Oct1 (B2) was strongest in mantle zone cells. C, interfollicular area displaying a majority of weakly positive Oct2 (C1) and BOB.1/OBF.1 (C3) cells. Basal layers within the epithelium expressed Octl (C2) and BOB.1/OBF.1 (A3) strongly, whereas Oct2 protein was missing (B1).

TABLE 2. Expression in Reactive Lymphoid Tissue

\begin{tabular}{|c|c|c|c|c|c|c|c|c|c|}
\hline \multirow[b]{2}{*}{ Factor } & \multicolumn{6}{|c|}{ Adult Reactive Tissue } & \multicolumn{3}{|c|}{ Thymus } \\
\hline & $\begin{array}{c}\text { Germinal } \\
\text { Center B } \\
\text { Cells }\end{array}$ & $\begin{array}{l}\text { Mantle } \\
\text { Zone B } \\
\text { Cells }\end{array}$ & $\begin{array}{c}\text { Marginal } \\
\text { Zone B } \\
\text { Cells }\end{array}$ & $\begin{array}{l}\text { Plasma } \\
\text { Cells }\end{array}$ & $\begin{array}{l}\text { Monocytoid } \\
\text { B Cells }\end{array}$ & $\begin{array}{l}\text { Interfollicular } \\
\mathrm{T} \text { Cells }\end{array}$ & $\begin{array}{l}\text { Cortical } \\
\text { Area }\end{array}$ & $\begin{array}{l}\text { Medullar } \\
\text { Area }\end{array}$ & $\begin{array}{c}\mathrm{B} \\
\text { Follicles }\end{array}$ \\
\hline Oct2 & +++ & ++ & ++ & +++ & +++ & $-1+$ & + & ++ & +++ \\
\hline Octl & ++ & + & ++ & +++ & + & + & ++ & ++ & ++ \\
\hline BOB.1/OBF.1 & +++ & + & + & +++ & ++ & $-1+$ & ++ & ++ & +++ \\
\hline
\end{tabular}

cells. For the purposes of this study, we only scored nuclear staining.

\section{RESULTS}

Oct2, Oct1, and BOB.1/OBF.1 Expression in Reactive Lymphoid Tissue

Germinal center B cells in reactive lymphoid tissue were characterized by a strong and ubiquitous Oct2 and BOB.1/OBF.1 protein expression. Almost all the cells of the germinal centers expressed Oct1, albeit weakly. For all three factors, a slight decrease in the intensity of the signal between the dark and the light zones within the germinal center was detectable (Fig. 1, Table 2).

In the mantle zone of reactive follicles, less intense reactivity for Oct2, Oct1, and BOB.1/OBF.1 than in germinal centers could be distinguished, although fewer cells were identified by the Oct1 antibody. In contrast, splenic marginal zone B cells showed intense Oct2 and Octl staining and a weaker signal for BOB.1/OBF.1. Monocytoid B cells showed Oct2 expression that was as intense as for germinal center cells and showed a lower level of 

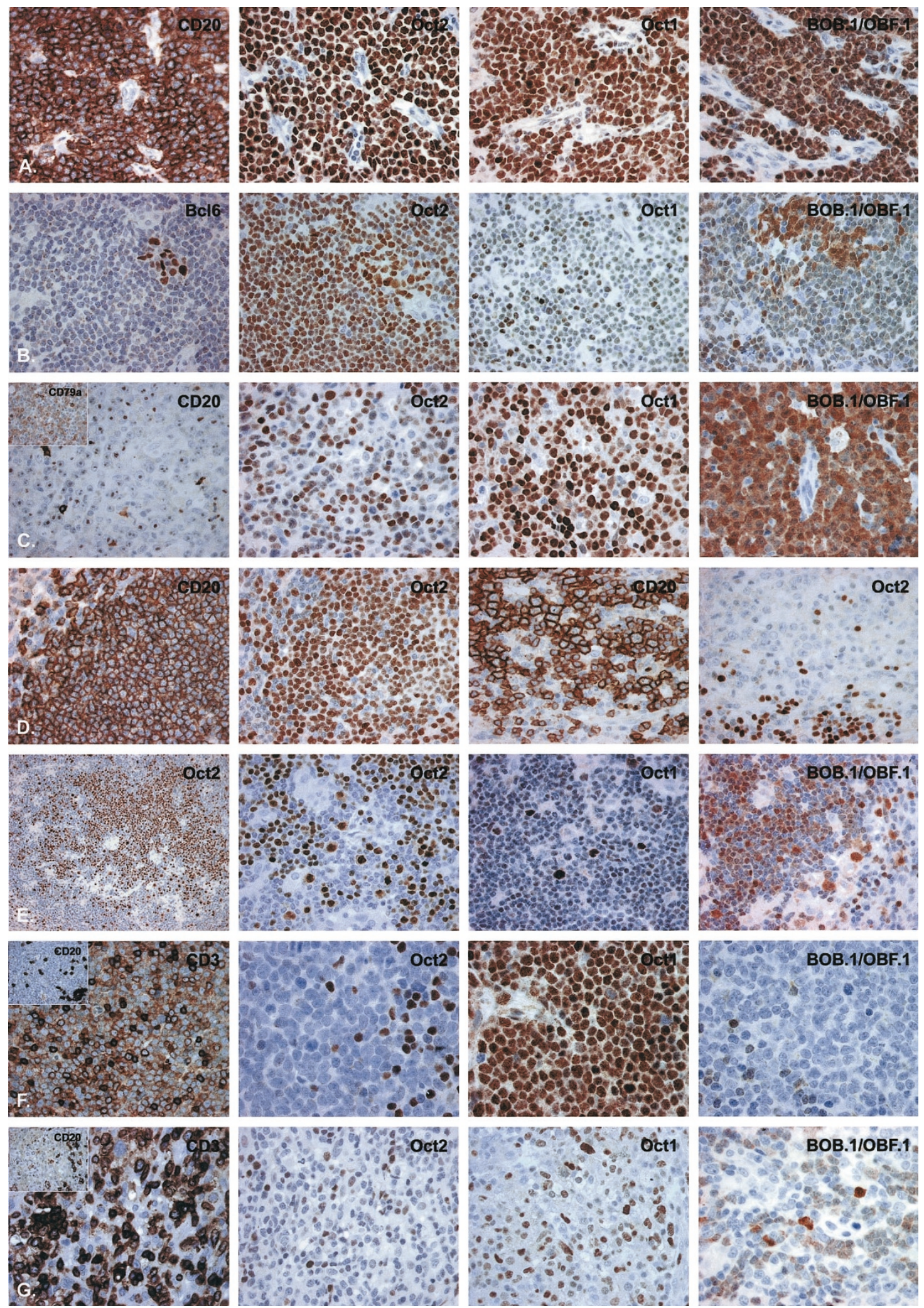

FIGURE 2. Immunohistochemical analysis of Oct2, Oct1, and BOB.1/OBF.1 expression in lymphomas. A, diffuse large B-cell lymphoma (DLBCL) case that is CD20 positive, showing a strong expression for Oct2, Oct1, and BOB.1/OBF.1. B, mantle zone lymphocyte case expressing Oct2, Oct1, and BOB.1/ OBF.1. The intensity of signal in the tumor was lower than that observed in residual reactive germinal center lymphocytes (shown using bcl-6 antibody). C, DLBCL CD20 negative case that is CD79a positive, displaying expression for Oct2, Oct1, and BOB.1/OBF.1. D, splenic marginal zone B-cell lymphoma CD20-positive case with expression of Oct2 and its progression to CD20-positive DLBCL with loss of Oct2 expression. E, lymphocyte-predominant Hodgkin's lymphoma case with lymphocytic and histiocytic cells (L\&H) cells showing similar Oct2 (low and high power), Oct1, and BOB.1/OBF.1 expression that found in reactive germinal center. F, T lymphoblastic lymphoma case, CD3 positive, with scattered CD20-reactive lymphocytes. Tumoral cells were Oct2 negative, strongly positive for Oct1, and BOB.1/OBF.1 negative. G, peripheral T-cell lymphoma CD3-positive case, with scattered CD20reactive lymphocytes, showing expression for Oct2, Oct1, and BOB.1/OBF.1. 
TABLE 3. Relation between the Expression of CD20 and Oct2, Oct1, and BOB.1/OBF.1 in HL

\begin{tabular}{|c|c|c|c|c|c|c|c|c|c|c|c|c|}
\hline \multirow{2}{*}{$\begin{array}{l}\text { CD20 } \\
\text { Status }\end{array}$} & \multicolumn{4}{|c|}{ Oct2 } & \multicolumn{4}{|c|}{ Oct1 } & \multicolumn{4}{|c|}{ BOB.1/OBF.1 } \\
\hline & +++ & ++ & + & - & +++ & ++ & + & - & +++ & ++ & + & - \\
\hline CD20- & 2 & 4 & 5 & 6 & 0 & 10 & 6 & 1 & 0 & 5 & 6 & 6 \\
\hline CD20+ & 8 & 3 & 0 & 1 & 4 & 5 & 3 & 0 & 1 & 7 & 3 & 1 \\
\hline
\end{tabular}

expression of Octl and a moderate BOB.1/OBF.1 signal. All three markers were distinctively and strongly expressed by plasma cells, with levels as high as in germinal center B cells. The majority of the interfollicular cells had a precise, albeit weak, expression of Oct2 and BOB.1/OBF.1 cells, and activated lymphocytes with larger nuclei were more strongly positive. Octl staining in the interfollicular area was ubiquitously weak.

Double immunostaining showed that reactivity for Oct2, Oct1, and BOB.1/OBF.1 was not restricted to CD20 cells. Thus, many interfollicular CD43expressing $\mathrm{T}$ cells expressed Oct2, BOB.1/OBF.1, and Octl proteins, although at a lower level of expression than was usually observed in B cells.

In the thymus, cortical thymocytes displayed strong Octl and BOB.1/OBF.1 expression, whereas Oct2 reactivity was weak. The intensity of Oct2 staining was slightly stronger in medullary thymocytes in which, additionally, expression of Octl and BOB.1/OBF.1 was distinct. B cells within the medullary lymphoid follicles had a similar immunophenotype to that described in the lymph node.

In all cases, dendritic cells, macrophages, endothelial cells, and the epithelial cells in skin, tonsil, thymus, and gastric and intestinal mucosa showed definite Octl and BOB.1/OBF.1 expression, but Oct2 reactivity was absent in all of these tissues. Within the epithelium, the expression was stronger in the proliferating cells in the basal layers, the neck of gastric glands, and the crypt bases of intestinal villi.

\section{Oct2, Oct1, and BOB.1/OBF.1 Expression in Lymphomas}

\section{B-cell lymphomas}

Most B-cell NHLs had the same phenotype, characterized by coexpression of Oct2, Oct1, and BOB.1/OBF.1. Two tumors (2/94) lacked Oct2 expression: one primary diffuse large B-cell lymphoma (DLBCL) and a DLBCL secondary to splenic marginal zone B-cell lymphoma (SMZL). Another two DLBCLs showed only weak expression. Octl displayed weak staining in 14 cases (9 DLBCLs, 2 mantle cell lymphomas [MCLs], 2 SMZLs, and 1 lymphoplasmacytic lymphoma [LpL]), and no case was considered to be entirely negative. All the analyzed cases were BOB.1/OBF.1 positive, although four cases displayed a weak signal (2 DLBCLs, 1
MCL, and $1 \mathrm{LpL})$. No case concurrently lacked Oct1, Oct2, and BOB.1/OBF.1, although one DLBCL sample showed simultaneous weak Octl and Oct2 expression (Fig. 2, Table 1).

Oct2 staining in benign tissues and malignant lymphomas had a selective differential pattern. Most B cells and B-cell lymphomas were clearly positive, although germinal center B cells stained most strongly. Because a high level of Oct2 expression could therefore be considered to be a marker of germinal center B cells and derived tumors, we reviewed the B-cell lymphoma cases characterized by strong Oct2 staining and found it to be present in all follicular lymphomas (FLs; 10/10), all Burkitt's lymphomas (BLs; 10/10), and a high proportion of DLBCL (33/47) cases. Oct2 staining was, in contrast, weaker or heterogeneous in other lymphoma types, such as MCLs, B-cell chronic lymphocytic leukemias (CLLs), SMZLs, or marginal zone lymphomas (MZLs), although it is noteworthy that a significant proportion of MZL, SMZL, and LpL cases displayed strong staining, with the same intensity as in FL cases. The relatively weak signal detected in MCL cases permitted the recognition of reactive germinal centers, highlighted by strong Oct2 staining. Other remarkable features were stronger staining in proliferating cells in different tumoral types, such as CLL (pseudofollicles or transformation centers), MCL (larger cells), and SMZL (proliferating cells within the marginal area). This differential Oct2 staining was an aid to recognizing the architectural pattern of CLL, MCL, and SMZL.

Generally, the intensity and number of Oct1positive cells in the tumors were lower than Oct2 expression. No B-cell lymphoma case was considered to be entirely Octl negative, although a proportion of cases had a very weak signal (14/94). Similar to the case with Oct2, all BL cases (10/10) showed distinctive and strong Octl staining, whereas FLs (4/10), DLBCLs (9/47), and other lymphoma types were more heterogeneous.

All B-cell lymphomas in this series expressed BOB.1/OBF.1 proteins, although the staining was significantly weaker in three cases.

To test the hypothetical value of these markers in the recognition of the B-cell lineage, all tumors were immunostained for CD20. This allowed us to establish that a group of cases with defective CD20 staining (4/4 LpL, 1/1 multiple myeloma, and 4/47 DLBCL with immunoblast or plasmablastic mor- 
phology) preserved the expression of these factors, except for one case of CD20-negative DLBCL, whose phenotype was Oct2-, Oct1++, and BOB.1/ OBF. $1++$. We confirmed the B phenotype by the presence of the CD79a marker and by demonstration of light-chain restriction in tumoral cells.

\section{T-cell lymphomas}

In TCL, 13/17 tumors showed reactivity for BOB.1/OBF.1 and at least one of the octamer motif regulator factors. The only constant factor present in TCL was Octl. The intensity of the signal and number of positive cells corresponding to Octl was higher than for Oct2 and BOB.1/OBF.1 in all cases of T-cell lymphoma analyzed. Oct2 expression was present in 11/17 tumors, and moreover, in some of these cases (6/11), the intensity and number of positive cells was lower than is usually observed in B-cell NHL. Angioimmunoblastic lymphoma was the TCL that most frequently expressed Oct2. BOB.1/OBF.1 was absent in four tumors, two of which coexpressed Oct2 and Oct1. The two extranodal NK/T-cell lymphomas analyzed did not show reactivity for BOB.1/OBF.1 (Fig. 2, Table 1).

To investigate the nature of the $\mathrm{T}$ cells expressing these factors, we performed double immunostaining with CD3 and CD43, verifying that a considerable proportion of tumoral cells expressed these proteins.

\section{Hodgkin's lymphoma}

To evaluate HL, we considered only ReedSternberg cells (RS) and lymphocytic and histiocytic cells $(\mathrm{L} \& \mathrm{H})$ cells, excluding the background of $\mathrm{B}$ and T lymphocytes. Of 25 HLs collected, we found that the most conspicuous of the three regulator elements analyzed was Oct1, which was present in 28/29 cases (Fig. 2, Table 1). However, the most strongly expressed factor in HL was Oct2, which was present in at least a definite proportion of the tumoral cells in 22/29 cases, although frequently the staining was heterogeneous, and only a fraction of all tumoral cells were positive. Expression was especially strong in the L\&H cells of LPHL, where the signal was as intense as that observed in reactive germinal centers. However, strong Oct2 staining could also be observed in classical forms of $\mathrm{HL}$ (four cases of mixed cellularity, some of which were classifiable as nodular lymphocyte-rich classical HL (NLRCHL). Seven of twenty-nine tumors were negative for the expression of BOB.1/OBF.1 protein. These seven tumors retained expression of Octl or Oct2.

Nodular sclerosis was the type of HL that was most often negative for some of these factors. Four of seven Oct2-negative HL and 2/7 BOB.1/OBF.1negative tumors belonged to the nodular sclerosis (NS) group. Indeed, the only case that had lost Oct1 factor expression was of the NS type. Moreover, RS cells in NS were characterized by their lower level of expression of both of these factors.

Five cases displayed an Oct2 \pm , Oct1 \pm , BOB.1/ OBF.1 \pm expression profile and were therefore characterized by weak or null expression of these transcription factors. In contrast, this expression profile was never observed within the B-cell NHL analyzed here.

Additionally, the intensity and number of cells showing reactivity for Oct2 and BOB.1/OBF.1 was extremely variable in each tumor, in contrast to the findings in $\mathrm{B}$ and $\mathrm{T}$ tumors. The expression of Octl was more constant in HL.

CD20 was present in a large proportion of the tumoral cells in 12/29 tumors. All CD20-positive cases displayed reactivity for Oct2 or Oct1, but one case lacked BOB.1/OBF.1 expression. Six of 17 CD20negative tumors were negative for BOB.1/OBF.1. In all cases with negative or low level of expression of all three proteins (Oct2, Oct1, and BOB.1/OBF.1), RS cells were CD20 negative (Table 3 ).

\section{DISCUSSION}

We analyzed the expression in human tissues and lymphoid tumors of three important proteins: Oct2, Oct1, and BOB.1/OBF.1. These are involved in the control of transcription of the Ig and other important lymphoid-specific genes, all of which are characterized by the harboring of transcriptional regulatory octamer motifs (1-4). This has now been facilitated by the availability of antibodies suitable for paraffin sections.

Reactive lymphoid tissue shows ubiquitous, nonB-cell-restricted, Oct1 expression, whereas Oct2 and BOB.1/OBF.1 appear to be expressed more strongly in B cells, and at a lower intensity in T cells. Both Oct2 and BOB.1/OBF.1 staining seem to recognize selectively germinal center B cells and interfollicular activated B cells. This pattern of expression is independent of the type of lymphoid tissue analyzed.

None of these transcription factors is B-cell specific; thus, in addition to the expression of these markers in other nonlymphoid tissues, Octl and BOB.1/OBF.1 recognize both cortical and medullary thymocytes, whereas Oct2 is expressed by medullary thymocytes. Similarly, the T-cell areas within lymph nodes show a weak but clear expression of all three markers, at least in a proportion of cells. Nevertheless, it has been demonstrated that in T-cell lines, this presence does not necessarily imply the active status of these proteins, which can be inhibited by phosphorylation (38).

The expression in tumoral lymphoid tissue seems to be essentially the same as in reactive tissue. 
Although the expression of Oct2 and BOB.1/OBF.1 is more intense in germinal center-derived B-cell lymphomas, such as follicular lymphoma and Burkitt's lymphoma, it is also present at a lower intensity in other B-cell lymphomas and even more weakly in T-cell lymphomas.

It is worth emphasizing that in all the BCLs studied, there were, at least at low levels, BOB.1/OBF.1 and either Oct1 or Oct2, in contrast to what has been observed in TCLs and HLs. Studies on BOB.1/OBF.1 knockout mice suggest that the presence of BOB.1/ OBF.1 is necessary to facilitate the development of germinal centers and Ig switching at adequate levels (43). It has recently been shown that depending on the sequence of the octamer motifs involved, Oct 1 and Oct2 homo- and heterodimers can transactivate promoters independently of BOB.1/OBF.1 presence, in different and specific steps of B-cell maturation (24). Thus, all the cases of BCL studied here, but not those of HL or TCL, appeared to retain the capacity to induce the expression of genes that are of key importance for germinal center differentiation and Ig switching $(32,42)$.

The expression patterns of Oct2 and BOB.1/ OBF.1 demonstrate that germinal center-derived BCLs show stronger staining for both markers, as has already been reported for BOB.1/OBF.1 (40), and confirms the germinal center origin of BLs, as previously suggested by the simultaneous expression of BCL- 6 and CD10.

The presence of both Oct2 and BOB.1/OBF.1 staining in a small group of CD20-negative B-cell lymphomas, including DLBCLs and multiple myelomas, implies a possible practical use for these antibodies in the recognition of the cell lineage of tumors lacking CD20 expression. An additional useful feature of the expression of these markers is facilitated by the stronger staining of proliferating cells. This allows the morphological patterns that are used in the differential diagnosis of the lymphoma types to be recognized.

The TCLs analyzed here show a constant expression of Oct1, with a lower frequency of Oct2 and BOB.1/OBF.1. All three markers were present at a lower intensity than was observed in BCLs, which seems to indicate a different role for these proteins in the T-cell lineage $(16,38)$.

The frequency and intensity of the expression of these markers in HL parallels the observations concerning CD20 expression in RS cells and Ig gene rearrangement, thus implying that the RS cells of HL are related to the B-cell lineage (27, $44)$. Additionally, the more intense expression of Oct2 in LPHLs could be interpreted as confirming the germinal center origin of tumor cells in this condition, as it has been already pointed out (29). Nevertheless, this germinal center origin, as suggested by the expression of Oct2, does not seem to be restricted to LPHLs because it can be observed in other forms of HL, especially in cases representative of what has been called nodular lymphocyte-rich classical HL (45), where the tumor cells have been claimed to be derived from germinal center cells (46).

Simultaneous analysis of these three proteins also shows that their expression pattern in HL is more deficient than that observed in BCL. This lends support to the interpretation that the lack of transcription of Ig genes in HL could be at least partially dependent on additional factors other than the presence of crippling IgH somatic mutations, as has been proposed by Stein and coworkers $(29,30,47)$. Small differences in the expression of Oct2 in classical forms of HL from this series and that recently published by Stein et al. (29) and by Re and colleagues (30) could be dependent on the selection of cases and on the use of different antibodies.

At this point, it is of interest to mention that the analysis of monocytoid B cells, a B-cell population lacking germinal center markers such as CD10 or bcl-6 and paradoxically negative for surface- or cytoplasmic-detectable Ig, revealed it to harbor a deficient expression profile of these factors, that is, characterized by strong Oct2 expression and by only a weak signal for both Octl and intermediate BOB.1/OBF.1. Thus, this mimics the phenotype occasionally observed in classic cases of HL. Indeed, one of the perplexing phenomena that characterizes MBCs is the lack of detectable surface or cytoplasmic immunoglobulin, as has been pointed out by different authors $(48,49)$.

In addition to these findings, one of the most notable results of this study is the strong expression of these markers in benign (germinal centers, thymus) and malignant (BL, RS cells in HL) proliferating cells, which supports the hypothesis of the existence of a tightly regulated, cell cycle-dependent expression of these proteins in lymphoid cells (13-15).

In summary, analysis of these transcription factors and the coactivator BOB.1/OBF.1 shows that within the lymphoid system, the expression of these proteins is not cell type specific but permits the identification of discrete expression profiles characteristic of specific differentiation steps. It also shows that B cells are usually characterized by the simultaneous presence of all these transcription factors, whereas TCL and HL have a deficient expression profile. Although not entirely cell specific, the strong nuclear expression of Oct2 and BOF.1/ OBF.1 by germinal center-derived lymphomas makes these antibodies a potentially useful tool in lymphoma diagnosis. 
Acknowledgments: We thank Cristina Romero, Mercedes Navarrete, Isabel Fernández, and María Jesús Acuña for their technical assistance and excellent help with laboratory work.

\section{REFERENCES}

1. Falkner FG, Zachau HG. Correct transcription of an immunoglobulin kappa gene requires an upstream fragment containing conserved sequence elements. Nature 1984;310: 71-4.

2. Parslow TG, Blair DL, Murphy WJ, Granner DK. Structure of the 5' ends of immunoglobulin genes: a novel conserved sequence. Proc Natl Acad Sci U S A 1984;81:2650-4.

3. Staudt LM, Lenardo MJ. Immunoglobulin gene transcription. Annu Rev Immunol 1991;9:373-98.

4. Scholer HR. Octamania, the POU factors in murine development. Trends Genet 1991;7:323-9.

5. Luo Y, Fujii H, Gerster T, Roeder RG. A novel B cell-derived coactivator potentiates the activation of immunoglobulin promoters by octamer-binding transcription factors. Cell 1992;71:231-41.

6. Franke S, Scholz G, Scheidereit C. Identification of novel ubiquitous and cell type-specific factors that specifically recognize immunoglobulin heavy chain and kappa light chain promoters. J Biol Chem 1994;269:20075-82.

7. Luo Y, Roeder RG. Cloning, functional characterization, and mechanism of action of the B-cell-specific transcriptional coactivator OCA-B. Mol Cell Biol 1995;15:4115-24.

8. Fletcher C, Heintz N, Roeder RG. Purification and characterization of OTF-1, a transcription factor regulating cell cycle expression of a human histone H2b gene. Cell 1987;51:77381

9. Scheidereit C, Heguy A, Roeder RG. Identification and purification of a human lymphoid-specific octamer-binding protein (OTF-2) that activates transcription of an immunoglobulin promoter in vitro. Cell 1987;51:783-93.

10. Shah PC, Bertolino E, Singh H. Using altered specificity Oct- 1 and Oct-2 mutants to analyze the regulation of immunoglobulin gene transcription. EMBO J 1997;16:7105-17.

11. Prabhu A, O'Brien DP, Weisner GL, Fulton R, Van Ness B. Octamer independent activation of transcription from the kappa immunoglobulin germline promoter. Nucleic Acids Res 1996;24:4805-11.

12. Malone CS, Patrone L, Buchanan KL, Webb CF, Wall R. An upstream Oct-1- and Oct-2-binding silencer governs B29 (Ig beta) gene expression. J Immunol 2000;164:2550-6.

13. Pfisterer P, Konig H, Hess J, Lipowsky G, Haendler B, Schleuning WD, et al. CRISP-3, a protein with homology to plant defense proteins, is expressed in mouse B cells under the control of Oct2. Mol Cell Biol 1996;16:6160-8.

14. Thevenin C, Lucas BP, Kozlow EJ, Kehrl JH. Cell type- and stage-specific expression of the CD20/B1 antigen correlates with the activity of a diverged octamer DNA motif present in its promoter. J Biol Chem 1993;268:5949-56.

15. Corcoran LM, Karvelas M. Oct-2 is required early in T cellindependent B cell activation for G1 progression and for proliferation. Immunity 1994;1:635-45.

16. Kang SM, Tsang W, Doll S, Scherle P, Ko HS, Tran AC, et al. Induction of the POU domain transcription factor Oct-2 during T-cell activation by cognate antigen. Mol Cell Biol 1992;12:3149-54.

17. Wirth T, Priess A, Annweiler A, Zwilling S, Oeler B. Multiple Oct2 isoforms are generated by alternative splicing. Nucleic Acids Res 1991;19:43-51.

18. Annweiler A, Zwilling S, Wirth T. Functional differences between the Oct2 transactivation domains determine the transactivation potential of individual Oct2 isoforms. Nucleic Acids Res 1994;22:4250-8.

19. Friedl EM, Matthias P. Transcriptional activation and repression, two properties of the lymphoid-specific transcription factor Oct-2a. Eur J Biochem 1995;234:308-16.

20. Liu YZ, Lee IK, Locke I, Dawson SJ, Latchman DS. Adjacent proline residues in the inhibitory domain of the Oct-2 transcription factor play distinct functional roles. Nucleic Acids Res 1998;26:2464-72.

21. Pevzner V, Kraft R, Kostka S, Lipp M. Phosphorylation of Oct-2 at sites located in the POU domain induces differential down-regulation of Oct-2 DNA-binding ability. Biochem J 2000;347:29-35.

22. Miller CL, Feldhaus AL, Rooney JW, Rhodes LD, Sibley CH, Singh H. Regulation and a possible stage-specific function of Oct-2 during pre-B-cell differentiation. Mol Cell Biol 1991; 11:4885-94.

23. Corcoran LM, Karvelas M, Nossal GJ, Ye ZS, Jacks T, Baltimore D. Oct-2, although not required for early B-cell development, is critical for later B-cell maturation and for postnatal survival. Genes Dev 1993;7:570-82.

24. Tomilin ARA, Lins K, Bak H, Vriend G, Wilmanns M, Schöler HR. Synergism with the coactivator OBF-1 (OCA-B, BOB-1) is mediated by a specific POU dimer configuration. Cell 2000;103:853-64.

25. Sturm RA, Das G, Herr W. The ubiquitous octamer-binding protein Oct- 1 contains a POU domain with a homeo box subdomain. Genes Dev 1988;2:1582-99.

26. Staudt LM, Singh H, Sen R, Wirth T, Sharp PA, Baltimore D. A lymphoid-specific protein binding to the octamer motif of immunoglobulin genes. Nature 1986;323:640-3.

27. Bargou RC, Leng C, Krappmann D, Emmerich F, Mapara MY, Bommert K, et al. High-level nuclear NF-kappa B and Oct-2 is a common feature of cultured Hodgkin/Reed-Sternberg cells. Blood 1996;87:4340-7.

28. Staudt LM, Clerc RG, Singh H, LeBowitz JH, Sharp PA, Baltimore D. Cloning of a lymphoid-specific cDNA encoding a protein binding the regulatory octamer DNA motif. Science 1988;241:577-80.

29. Stein H, Marafioti T, Foss HD, Laumen H, Hummel M, Anagnostopoulos I, et al. Down-regulation of BOB.1/OBF.1 and Oct2 in classical Hodgkin disease but not in lymphocyte predominant Hodgkin disease correlates with immunoglobulin transcription. Blood 2001;97:496-501.

30. Re A, Müschen M, Ahmadi T, Wickenhauser C, StaratschekJok A, Holtick U, et al. Oct-2 and Bob-1 deficiency in Hodgkin and Reed Sternberg cells. Cancer Research 2001;61: 2080-4.

31. Stevens S, Ong J, Kim U, Eckhardt LA, Roeder RG. Role of OCA-B in 3'-IgH enhancer function. J Immunol 2000;164: 5306-12.

32. Laumen H, Nielsen PJ, Wirth T. The BOB.1/OBF.1 coactivator is essential for octamer-dependent transcription in B cells. Eur J Immunol 2000;30:458-69.

33. Strubin M, Newell JW, Matthias P. OBF-1, a novel B cellspecific coactivator that stimulates immunoglobulin promoter activity through association with octamer-binding proteins. Cell 1995;80:497-506.

34. Gstaiger M, Knoepfel L, Georgiev O, Schaffner W, Hovens CM. A B-cell coactivator of octamer-binding transcription factors. Nature 1995;373:360-2.

35. Chang JF, Phillips K, Lundback T, Gstaiger M, Ladbury JE, Luisi B. Oct-1 POU and octamer DNA co-operate to recognise the Bob-1 transcription co-activator via induced folding. J Mol Biol 1999;288:941-52.

36. Krapp A, Strubin M. B-cell coactivator OBF-1 exhibits unusual transcriptional properties and functions in a DNA- 
bound Oct-1-dependent fashion. Mol Cell Biol 1999;19: 4247-54.

37. Sauter P, Matthias P. Coactivator OBF-1 makes selective contacts with both the POU-specific domain and the POU homeodomain and acts as a molecular clamp on DNA. Mol Cell Biol 1998;18:7397-409.

38. Zwilling S, Dieckmann A, Pfisterer P, Angel P, Wirth T. Inducible expression and phosphorylation of coactivator BOB.1/OBF.1 in T cells. Science 1997;277:221-5.

39. Schubart DB, Sauter P, Massa S, Friedl EM, Schwarzenbach $\mathrm{H}$, Matthias P. Gene structure and characterization of the murine homologue of the B cell-specific transcriptional coactivator OBF-1. Nucleic Acids Res 1996;24:191320.

40. Greiner A, Muller KB, Hess J, Pfeffer K, Muller-Hermelink HK, Wirth T. Up-regulation of BOB.1/OBF.1 expression in normal germinal center B cells and germinal center-derived lymphomas. Am J Pathol 2000;156:501-7.

41. Stevens S, Wang L, Roeder RG. Functional analysis of the OCA-B promoter. J Immunol 2000;164:6372-9.

42. Qin XF, Reichlin A, Luo Y, Roeder RG, Nussenzweig MC. OCA-B integrates B. cell antigen receptor-, CD40L- and IL 4-mediated signals for the germinal center pathway of B cell development. EMBO J 1998;17:5066-75.

43. Kim U, Qin XF, Gong S, Stevens S, Luo Y, Nussenzweig M, et al. The B-cell-specific transcription coactivator OCA-B/OBF$1 / \mathrm{Bob}-1$ is essential for normal production of immunoglobulin isotypes. Nature 1996;383:542-7.

44. Hummel M, Ziemann K, Lammert H, Pileri S, Sabattini E, Stein H. Hodgkin's disease with monoclonal and polyclonal populations of Reed-Sternberg cells. N Engl J Med 1995;333: 901-6.
45. Anagnostopoulos I, Hansmann ML, Franssila K, Harris M, Harris NL, Jaffe ES, et al. European Task Force on Lymphoma Project on Lymphocyte Predominance Hodgkin Disease: histologic and immunohistologic analysis of submitted cases reveals 2 types of Hodgkin disease with a nodular growth pattern and abundant lymphocytes. Blood 2000;96: 1889-99.

46. Ashton-Key M, Thorpe PA, Allen JP, Isaacson PG. Follicular Hodgkin's disease. Am J Surg Pathol 1995;19:1294-9.

47. Marafioti T, Hummel M, Foss HD, Laumen H, Korbjuhn P, Anagnostopoulos I, et al. Hodgkin and Reed-Sternberg cells represent an expansion of a single clone originating from a germinal center B-cell with functional immunoglobulin gene rearrangements but defective immunoglobulin transcription. Blood 2000;95:1443-50.

48. Stein K, Hummel M, Korbjuhn P, Foss HD, Anagnostopoulos I, Marafioti T, et al. Monocytoid B cells are distinct from splenic marginal zone cells and commonly derive from unmutated naive B cells and less frequently from postgerminal center B cells by polyclonal transformation. Blood 1999;94: 2800-8.

49. Camacho FI GJ, Sánchez-Verde L, Sáez AI, Sánchez-Beato M, Mollejo M, Piris MA. Unique phenotypic profile of monocytoid B cells. Differences in comparison with the phenotypic profile observed in marginal zone B cells and so-called monocytoid B cell lymphoma. Am J Pathol 2001; 158:1363-9.

50. Harris NL, Jaffe ES, Stein H, Banks PM, Chan JK, Cleary ML, et al. A revised European-American classification of lymphoid neoplasms: a proposal from the International Lymphoma Study Group. Blood 1994;84:1361-92. 